\title{
Student experiences in traditional and active learning classrooms in introductory physics courses
}

\author{
Whitney Faries, ${ }^{1}$ Robin Gordon, ${ }^{2}$ and Benjamin W. Dreyfus ${ }^{1,3}$ \\ ${ }^{1}$ Department of Physics and Astronomy, George Mason University, 4400 University Drive, Fairfax VA 22030, USA \\ ${ }^{2}$ Department of Biology, George Mason University, 4400 University Drive, Fairfax VA 22030, USA \\ ${ }^{3}$ STEM Accelerator Program, George Mason University, 4400 University Drive, Fairfax VA 22030, USA
}

The interaction between course environments and student responses can be complex. We look at two different sets of classes - algebra-based and calculus-based introductory physics. The focus is on students who went from the traditional classroom for one course to an alternative style for the next in the sequence, as well as feelings regarding interactive elements interwoven into large-enrollment lecture classes. Individual interviews with students allowed us to examine the elements of the instructional environment that have impacts on students' attitudes.

\section{INTRODUCTION}

Active-learning methods have been shown to support student learning across a variety of undergraduate physics contexts [1], both in fully transformed courses and in traditionally structured courses that incorporate some interactive-engagement elements. However, questions of student buy-in are often present, as students adjust to learning environments that depart from their expectations [2].

A number of studies $[3,4]$ have quantitatively observed attitudes in introductory physics courses using pre- and post-tests. We took a qualitative approach with postinterviews, and also found that students can come into college with confusion and incorrect ideas about how to do physics.

In practice, active-learning courses operate within larger ecosystems, and individual students in active-learning courses also take traditional courses before, after, or at the same time, and so understanding these transitions between types of course environments is essential to understanding the students' full experience. McPadden and Brewe [5] looked at the representation choices made by students in the second semester of Modeling Instruction, and sorted out which students had been in the traditional vs. Modeling courses for the first semester. In this interview-based study, we similarly look at students who went from traditional to active-learning courses, and focus on their attitudes and experiences in the courses. The long-term goal of this research is to further our understanding of this kind of transition and to look at student attitudes in courses that have active learning elements.

\section{METHODS}

In the 2017-2018 school year, students from different classes were invited to meet with two of the authors to share their opinions about the class via interview. The purpose of these interviews was to gain an intimate understanding of the student perspective in different formats of physics classrooms. The interviews were audio recorded to allow for written transcriptions.

Interviews were conducted in College Physics I and II (CP1 and CP2) which is an algebra-based physics course geared towards non physics majors. Students from these consecutive courses were invited to participate in a confidential one-on-one interview. The interviews lasted for 15-20 minutes and students were asked questions regarding their experience in the course. The CP1 and CP2 course does not offer an alternative classroom setting but instead take place in a lecture hall with an average class size of 210 students. Classroom tactics were used to promote active learning throughout the teaching of these courses. Instead of the professor lecturing for the entirety of the class, questions were interwoven throughout the PowerPoint presentation. Students received participation credit for working through these problems and punching in their answer using a clicker. The students would interact with each other and with learning assistants to answer the questions. The grading was based solely on participation and students were not penalized for an incorrect answer.

Another class that was observed was PHYS160: University Physics 1 . This is a calculus-based physics course aimed at engineering, mathematics, physics, and astronomy majors. The average class size is 170 students for the traditional classroom and 72 for the ALT section. There are two Learning Assistants. It will now be referred to UP. Each semester, multiple sections of this class are offered: one or more traditional lecture sections, and one flipped section taught in an Active Learning with Technology (ALT) classroom and supported by undergraduate Learning Assistants (LAs). For Fall 2017, eight interviews were conducted with three students in the traditional lecture and five from the active learning section. 
Each interview lasted about 10-15 minutes and consisted of questions such as:

"How many hours outside of class are you spending on physics each week?"

"What do you like best about the section you are in?"

"Do you study in a group or individually?"

"Do you work better with others or by yourself?"

The author made note of keywords or phrases such as "I struggle with...", "I don't like...", and the use of words like "stressed", and "enjoy". These particular words would indicate positive or negative attitudes. The frequency of these words and phrases was used to indicate class-wide trends.

The first author also made observations during the class to note any interesting behaviors or statements from the students. An example of a noteworthy behavior would be a student discussing how much he/she enjoyed working with others or a student saying he/she wishes they'd taken a different section. A few of these statements were recorded, but nearly all were positive towards the active-learning classroom. In class, students seemed to enjoy working with classmates towards solving an assigned problem.

Likewise, the classroom observations were used to indicate trends. The frequency of interesting behaviors or statements was used to gauge class-wide trends and to back up themes found in interviews

In CP1, eight interviews were conducted. Questions during these interviews included:

"Have the students you sit near and the LA's been helpful in helping you understand complex physics subjects?"

"Has classroom time doing problems and iClicker questions been an effective way for you to learn?"

"How has your experience been taking exams?"

In CP2, the same method of interviews was conducted. These interviews followed many of the same students who chose to take the physics courses consecutively. The interviews were anonymized and kept confidential until after final grades were posted

The process was repeated the following semester in UP2. Seven interviews were conducted (four of these were with students interviewed in the previous semester); five of these students had transitioned from the traditional section to the active learning with technology (ALT) section. The remaining two students were used to better understand the classroom dynamic. For this round, the questions centered around the differences in experience between the two classes. A few example questions are:

"Which section do you prefer and why?"

"Are there any changes to your study habits as a result of switching sections?"
"How do you feel about the interactive aspects of the alternative learning classroom compared to the lecture style?"

In medical physics 2 , five interviews were held.

Questions during these interviews included:

"Do you feel like you have developed more effective study skills this semester?"

"Do you have anything else to add about your classroom experience?"

Following the interviews, the recordings were transcribed and analyzed.

\section{RESULTS AND DISCUSSION}

A particularly interesting student took part in both sets interviews. John (all names are pseudonyms) took UP1 three times before passing. He gave the authors valuable insight into how students transition and change between the courses. John enrolled in the traditional lecture style classroom in Spring 2016 and Fall 2017, and he received a $\mathrm{D}$ both times. In his first interview, he described his study habits as "minimal" and primarily did the homework hours before it was due. He did not interact with the professor or the learning assistants and did not study with other students.

When asked about why he felt he didn't pass the class, he admitted that because of his major, he didn't see the relevance of physics to his degree. For John, there was no incentive to learn the material, and the traditional classroom allowed him to do the minimal amount of work.

In Fall 2017, he enrolled in the active learning classroom to take UP1 a third and final time. John received a final grade of an A. When asked to what he attributed the drastic change in grades, he cited the classroom style. The alternative classroom did not allow him to "slack off and not prepare for class ahead of time;" there were weekly required readings that were essential to understanding the class, as there was no lecture of the material. If he didn't prepare before class, it was very obvious to his classmates and to his professor. John came to class with a loose understanding of the material, which he was able to build upon with his classmates as they collaborated on problems.

Another key contributor was the professor-student relationship. In the active learning classroom, students can receive direct feedback from the professor. This allowed John to form a relationship with the professor that he was unable to make during his semesters in the traditional classroom. As a result, he was much more comfortable asking for help. "The first semester I took the class, I was too scared and intimidated by the professor to ask for help. I'm taking 160 for the third time with the same professor, and this time he knows my name and I feel better about going to office hours and speaking up in class." 
The following semester in UP2, John received another A after participating in the second round of interviews. In the interview, he again cited the alternative learning classroom for his success. "I think that this type of classroom really appeals to me, and I'm thankful that [a friend] encouraged me to sign up after finding out that I failed twice before. I'm not sure I'd be in the same position if I tried to take the traditional lecture again."

John's interviews were used to identify any key ideas that might resonate with his classmates.

A general consensus of UP1/2 interviews was a preference of the active learning section over the traditional lecture section. Students enjoyed the collaborative aspects because it allowed them to clarify their understanding of the material through their peers. Another student from this class, Anna, said, “if I'm reading and I don't understand something, I know my tablemates can help. They also do the readings, and everybody has different things that stick with them, so usually someone can help me. If not, then I know [the professor] and [the learning assistants] can help." This quickly resolves any confusion on the material. Likewise, the student can interact with the professor more directly to ask further questions.

Another benefit of this style of classroom was the students were able to see different approaches to the problems. This allowed them to figure out the best ways to tackle the concepts and to be creative in solving them. This exposure helped students to see different ways to apply the physics and grasp a better understanding of the material. This idea was outlined in the transcript below from another student, Emily:

Interviewer: What are some of the benefits to taking the ALT section?

Emily: I like working the problems with lots of different people. Like, everyone has different ideas where to start and how to solve and why to do this or that. But most of the time they're wrong, but I can learn from that, you know?

I: So you're able to see others' mistakes and take something away from that?

E: Yeah, I learn how not to do the problems.

I: Yeah, that's a useful thing for this class.

$E$ : And most of the time, the mistakes they make are ones I would've. So it's not like they're completely out of left field.

E: Sometimes it's also easier to see the main ideas when you're working in a group. Like with Newton's laws, the $F=$ ma thing, you can figure out that the first thing you need to do it solve for acceleration in terms of tension and then plug that in and then do this other thing and boom, done.

I: Your tablemates helped you formulate that?

E: Yeah, absolutely.
During the interviews conducted in CP1/2, trends among responses were analyzed with specific emphasis on how students viewed the active learning methods that were used in the course. In CP1, students were asked if clicker questions had been an effective way to learn. Katie appreciated the interactive style and said, "Yes, I love doing problems in class and I think it is a good use of class time. Most teachers just lecture so I like this new style of learning. It allows me extra time to practice during class when normally I would be expected to do problems outside of class time." Katie was also asked about taking exams. In $\mathrm{CP} 1$, exams are administered in a large lecture hall. When asked about her exam taking experience she said that, "I like the structure but I don't like to take exams in a big lecture hall. I understand that this problem can't really be changed but I just get so distracted easily by people around me."

Jerry, another student who was interviewed CP1, shared similar views. When asked the first question about clicker questions he said that it had been an effective use of class time, "Yes, as it sets me straight, so I know if I'm doing the right thing and thinking about the problem in the correct way." When asked about the exams he also mentioned the size of the class, "I am not a fan of exams in the lecture hall setting as the desks are very small and we are very close to each other so for me it is more stressful than it needs to be. Also, I really do not like the class size for this type of learning as for me I like one-on-one instruction. I would like to see exams taken in another type of setting, so I can focus on the material rather than the other stuff I mentioned."

Greg, another CP1 student, liked using the clicker to do conceptual problems, "Maybe the math ones are not super helpful but the conceptual problems really help. For example, the elevator problems (referring to a problem about normal force and weight) are helpful to do in class." He also mentioned the clickers when answering the question on exams, "I like the clicker questions and I'm glad they aren't for accuracy. I think doing the clickers helped with my score on the exam. They helped me practice problems and make sure I understood them well."

The trends in the CP1 responses suggest that students find that they benefit from the use of active learning methods like clickers to practice problems during lecture. Smaller class size could also benefit students when it comes to test taking. Having one-on-one time with peers also seems beneficial to students when practicing problems and learning hard concepts.

In CP2, Megan was interviewed. Megan is a pre-med student who enjoyed taking physics in high school. During the interview, she described her experiences taking physics in 
high school, "My teacher in high school was amazing so I felt like I already knew a lot of the topics last semester." When asked about how her study habits had changed when transitioning from CP1 to CP2 she said that, "Last semester was more reinforcement from high school... This semester has a lot of new material that I have to work harder to comprehend." Megan was having a hard time adapting to the new material and described some of the changes she had made to her study habits: "What I do is I study with a group of people and I feel like that it is more effective than when I study by myself ... When I study with other people they question things about the subject that I wouldn't have questioned if I was by myself and make me realize that I need to practice the material more." When asked if she has anything else to add to the interview she said, "I feel like it's hard in general for professors to teach physics. For this semester he would give us a problem and we would use the clickers to put in our answer. I don't really like this method because I feel like we don't have time to really work through and think about the problem. I have to take time to go over it and figure it out after class. In high school, the class setting was smaller and my teacher would put up a problem and give us five to ten minutes to work through the problem and then go through it step by step. The exams would be really hard but I felt really confident and like I really understood it because I took the time in class to understand the problem by working through it."

Megan used group study meetings to practice material and found it helpful when going over topics to reinforce her understanding. The experience she had in high school was very different from the experience she had in CP1 and CP2. Although the ALT classroom isn't offered for CP1 and CP2, Megan seems like she would benefit from this sort of setting because she prefers a smaller class size. Although the courses did offer some active learning methods like clickers, Megan reported that she didn't benefit from the clicker questions because she didn't have enough time to work through the problems in class.

\section{CONCLUSIONS AND IMPLICATIONS}

In UP1 and UP2, the students interviewed perceive the active learning classroom format to be most effective. The students who volunteered to be interviewed are not necessarily a representative sample of the class as a whole (for example, students with a more positive view of the course may be more likely to volunteer for interviews), so we cannot generalize from these students to the entire student population, but we can look at which particular aspects stood out most for these students. The students who were interviewed generally showed a positive attitude towards the active-learning format because of the collaborative aspect. This helped students deepen their understanding of the material and develop relationships with the professors and learning assistants. These relationships made students feel more comfortable when seeking help.

Students in CP1 liked using clickers and mentioned that it was a good way to learn problems. When taking tests, the students mentioned that a smaller setting would allow them to better focus on the exam. In CP2, Megan mentioned that she found working in groups outside of class is helpful in reinforcing information. Megan also talked about how she preferred the environment of her high school physics class where she would spend a lot of time working on problems as a class. Megan may benefit from an alternative classroom setting where they work in smaller groups and the attention is more one-on-one.

This initial study identifies some of the relevant factors that influence the experience of students who switch from traditional to active-learning introductory physics courses, based on a small number of interviews. Future work will expand on this and use these initial categories as a basis for a larger-scale study.

A suggestion for instructors would be to incorporate more collaborative aspects into traditional lecture courses. This might encourage student collaboration and increase student understanding of introductory physics. Examples of this are in-class group work assignments, in-class participation points awarded by answering questions with or without the help of classmates, and if possible, smaller class sizes to allow more professor-student interactions.

\section{ACKNOWLEDGEMENTS}

This work was supported in part by the Undergraduate Research Scholars Program at George Mason University.

[1] C. Hoellwarth, M. Moelter, and R. Knight, Am. J. Phys., 73, 459 (2005).

[2] J.D.H. Gaffney and A.L.H. Gaffney, Phys. Rev. PER 12, 020125 (2016).

[3] E.F. Redish, J.M. Saul, and R.N. Steinberg, Am. J. Phys. 66, 212 (1998).

[4] W. K. Adams, K. K. Perkins, N. S. Podolefsky, M. Dubson, N. D. Finkelstein, and C. E. Wieman, Phys. Rev. ST Phys. Educ. Res. 2, 010101 (2006).

[5] D. McPadden and E. Brewe, Phys. Rev. PER 13, 020129 (2017). 